\title{
Pilar Monzó de la Roca, dona sainetera
}

\author{
[Pilar Monzó de la Roca, a woman sketch writer]
}

\author{
ROBERT MARCH \\ Universitat de València \\ robert.march@uv.es
}

Resum: En aquest article ens proposem realitzar un recorregut per la figura de Pilar Monzó de la Roca, sainetera dels anys trenta del segle passat, de qui existeix molt poca documentació. A més, prestem atenció a dos de les seues obres, concretament, La falta de Marieta i Visanteta, ambdues estrenades l'any 1930, en les quals observem diferents trets d'alguns dels personatges femenins.

Paraules clau: Pilar Monzó, dramatúrgia de dones, sainet, anys trenta, memòria.

Aвstract: In this article we take a summary of the figure of Pilar Monzó de la Roca, a saineteer from the 1930s, of whom there is very little historical documentation. In addition, we focus on two of her works, specifically, La falta de Marieta and Visanteta, both of them premiered in 1930, in which we observe different features of some of the female characters.

KeYwords: Pilar Monzó, women playwriting, one act play, 30s, memory

*Aquest article ha estat possible gràcies a l'ajuda de Fernanda Medina, del Centre de Documentació Teatral de València; la investigadora i docent Jana Pacheco; la periodista Laura Bellver; l'escriptora Rosa Roig; la professora i investigadora teatral Fàtima Agut; el dramaturg i director d'escena Xavier Puchades i les dramaturgues Paula Llorens i Antonia Bueno.

Recepció: I8/05/2020. Acceptació: 28/06/2020. Publicació: 27/07/2020

REVISTA VALENCIANA DE FILOLOGIA / IV (2020) p. 95-IO8 / ISSN 0556-705X DOI I0.28939/RVF.V4.I32 


\section{Introducció}

Endinsar-se en els estudis que abasten la memòria teatral — qualsevol memòria- és ser conscients que es trepitja un terreny no massa ferm, mòbil, volàtil, podríem dir. Però, no obstant això, paga la pena viure l'experiència si l'objectiu és el de portar al present una llum —unes cuques de llum, diria Didi-Huberman- que durant prou de temps ha romàs velada. Ara bé, tot i ser sabedors que el pas del temps es cobra alguna penyora, detalls grans o insignificants dels quals encara hui no sabem gran cosa, assumim, humilment, el risc de rescatar, per poc que siga, la figura de la dramaturga de sainets, Pilar Monzó de la Roca. I diem per poc, perquè el seu nom, com el de milers d'altres dones, ha quedat pràcticament esborrat dels llibres d'història, escrita quasi sempre, no és original dir-ho, per homes blancs i heterosexuals i, normalment, amb cert poder.

$\mathrm{Ha}$ calgut, llavors, esperar estudis recents per poder esbrinar algun fil sobre Monzó. Estudis més propers, però, també d'altres mirades, més aviat col-lectives i no sempre pertanyents als interessos del món de l'acadèmia. En tot cas, gaudim, per exemple, dels dos volums que Juan Antonio Hormigón, junt amb Inmaculada Alvear i Carlos Rodríguez, va dedicar a les autores teatrals sota el títol Autoras en la historia del teatro español, en què, el segon volum, recull unes notes breus sobre Monzó; la fitxa biogràfica de Dèlia Amorós, que es troba al Diccionari biogràfic de dones, ${ }^{1}$ integrada dins el portal web de la Xarxa Vives, de la Generalitat de Catalunya i del Consell de Mallorca, que beu i es fa ressò del manual d'Hormigón, la iniciativa de Clásicas y Modernas, una associació de dones que, a les darreries de l'any 2018, a la seu de l'SGAE de València, amb el lema de «Rebeldes y transgresoras», va realitzar un acte d'homenatge a la nostra dramaturga, però, també a Matilde Salvador, Rosalía de Castro, Rosario de Acuña i Carmen Burgos, per tal de traure de l'oblit el llegat de les dones escriptores. A més a més, l'any passat, l'escriptora Rosa Roig va realitzar una adaptació de La falta de Marieta, un dels sainets de Monzó, que

1 Diccionari biogràfic de dones $=D B D$.

REVISTA VALENCIANA DE FILOLOGIA / IV (2020) p. 95-IO8

ROBERT MARCH

Pilar Monzó de la Roca, dona sainetera / 96 
ha estat publicada en el llibre de falla de l'Associació Cultural Bda. Sda. Família Corea, en què la intenció, tal com assenyala Roig, ha estat traure de l'oblit la dramaturga i presentar una lectura actualitzada mantenint les característiques del gènere.

A pesar de les dificultats en la recerca de documentació, l'interés per Monzó segueix present. Així mateix, Lacueva, en la seua tesi doctoral, recollia unes paraules d'una ponència de Lliris Picó, M. Ángeles Herrero i Gabriel Sansano, que, l'any 2005, dedicaven a les saineteres valencianes en temps de preguerra i guerra. Recuperem, a continuació, un fragment d'aquella ponència, extreta, justament, de la tesi de Lacueva suara esmentada:

Con todo, es sin duda Pilar Monzó de Roca la autora que posee una obra más extensa, que se desarrolló con una cierta regularidad, sobre todo, entre 1929 y 1932. Su producción dramática conocida hasta el momento comprende los sainetes Vicenteta, publicado en 1931 y estrenado un año después; La falta de Marieta, publicado en Valencia (sin fecha) y estrenado en 1930; El geni de Tana, publicado también en Valencia (sin fecha) y estrenado durante la época republicana (1931-1936); Pare... Pare... (1932), estrenado en 1932 y El amo, publicado en Valencia (sin fecha), estrenado durante los años treinta. Además de estas obras conocidas, nosotros hemos tenido noticia al menos de tres obras más: Calor de niu y La nóvia de Paquito, ambas estrenadas en 1933 y Un bateig ( estreno ni edición) (Lacueva 2013: 45).

Actualment, aquesta informació pot actualitzar-se a l'Inventari bibliogràfic informatitzat del teatre popular valencià dels segles XIX $i$ XX (1817-1850), dirigit per Gabriel Sansano, que pot trobar-se en xarxa. D'acord amb Roig, Monzó fou la més prolífica de les dones saineteres que es coneixen hui dia, «forma part d'una curta però ben sucosa nòmina d'autores valencianes que van escriure i van estrenar peces teatrals amb èxit (2019: 170)». I així les coses, el teatre popular dels segles XIX i XX escrit per dones segueix sent desconegut per gran part del País.

REVISTA VALENCIANA DE FILOLOGIA / IV (2020) p. 95-IO8

ROBERT MARCH

Pilar Monzó de la Roca, dona sainetera / 97 


\section{Pilar Monzó de la Roca, dramaturga dels trenta}

Si agafem l'estudi d'Hormigón, ben aviat ens adonem de la manca de dades biogràfiques que es conserven en el cas de Pilar Monzó. De fet, són pràcticament inexistents. Ara bé, si cert que es desconeix la data i el lloc de naixement, també ho és que sabem que va escriure i publicar als anys vint i trenta del segle passat. ${ }^{2}$ En tot cas, a més del conjunt de dones saineteres (Maria Luisa Camilleri, Vicenta Matalí, Empar Royo...), Hormigón destaca de Monzó el seu domini dels recursos dramatúrgics en l'escriptura del sainet, eines que són semblants a les que poden trobar-se en altres sainets de l'època, existeix en ells, segons Hormigón, una confiança en el poble i en les classes baixes, que no abandona el costumisme de l'època i, alhora, es presenta antiquat, indica l'investigador, inclús per al moment.

Aunque los esquemas dramáticos que utiliza Pilar Monzó son los mismos dels sainete castizo madrileño o andaluz típicos del genero Chico de finales del siglo pasado, con su mismo fondo melodramático y populista, su confianza en la bondad del pueblo llano frente a los señoritos y su glorificación de la patria chica, lo cierto es que la autora sabe darles un carácter muy valenciano mediante una observación muy rigorosa de los distintos lenguajes (valenciano de ciudad, valenciano de la huerta, castellano...) y de los tipus populares. El resultado, aunque anticuado en los años $20 \mathrm{y}$ 30 , es un teatro agradable, divertido, donde restaltan los valores costumbristas (Hormigón 1996: 889).

En certa mesura, aquesta bondat podria veure's reflectida en les paraules que l'autora dedica a la revista Nostre Teatro, en què, més que pensar en la seua producció, confessa confiar en els intèrprets:

2 La investigadora teatral d'Almassora i professora jubilada d'Educació Secundària, Fàtima Agut, en una conversa recent, ens comunicava com la seua dèria per aprofundir en la figura de Monzó sempre havia resultat àrdua, tot just per les dificultats que hem esmentat. En tot cas, en algun moment, Agut va poder llegir que Pilar Monzó va arribar a ser mestra d'algun poble de Terol o de Castelló, però, en aquest cas, fronterer amb Terol, tot i que sempre se l'ha relacionada amb València.

REVISTA VALENCIANA DE FILOLOGIA / IV (2020) p. 95-IO8

ROBERT MARCH

Pilar Monzó de la Roca, dona sainetera / 98 
Quan escric un llibre no pense mai en que puga agradar el que jo he fet. Pense sempre i confie en la moltíssima voluntat i el grandíssim art dels que interpreten les meues obres (Roig 2019, 170).

Així mateix, seguint Hormigón, Amorós deixa constància en el $D B D$ que a Monzó se li atribueixen nou obres teatrals estrenades en diferents teatres de València durant els anys trenta, cosa que ens evidencia que la dramaturga va formar part d'aquells valencians que van creure en «el teatre com a eina fonamental per a la consolidació de la Renaixença». ${ }^{3}$ Segons Amorós:

Les seues obres tenen un accentuat caràcter tradicional i un ús arcaïtzant de la llengua. L'autora tendeix a crear una dinàmica d'identificació entre els espectadors i determinats personatges a través del funcionament arquetípic d'aquest. El llenguatge és entenedor i les sobres tendeixen a la comicitat com a principal element per a requerir l'atenció dels espectadors. ${ }^{4}$

De les obres reconegudes a Monzó i recollides al $D B D$, que també hem esmentat gràcies al fragment de la conferència citat per Lacueva, prestarem atenció a La falta de Marieta i Visanteta, ambdues del 1930.

\section{3. 'La falta de Marieta' (1930, Salón Novedades)}

Sainet estrenat el 25 de març de 1930 al Salón Novedades de València. La peça, amb música de José Jarque Cullado, està dedicada a l'actor Manuel Taberner amb les paraules següents: "primer prestigio de la escena valenciana, con todo afecto y generación» (Monzó 1930: 3). En tot cas, l'autora també expressa el seu reconeixement al senyor Belloch, empresari de l'espai en què fou estrenada la peça.

3 DBD, fitxa de Pilar Monzó de la Roca.

4 Opere citato.

REVISTA VALENCIANA DE FILOLOGIA / IV (2020) p. 95-IO8

ROBERT MARCH

Pilar Monzó de la Roca, dona sainetera / 99 
L'obra, publicada en la Imprenta La Gutenberg, es presenta en acte únic $i$ es divideix en onze escenes, de les quals la setena i la novena inclouen música. Pel que fa als personatges, n'hi ha onze: Maria, 25 anys, mestra de modistes (Enriqueta Delas); Doloretes, 30 anys, encarregada del taller de moda (Pura Millet); Visanteta, 47 anys, romàntica, que vist de manera cursi (Vicenta Silvestre); Marieta, 14 anys, aprenenta (Encarna Máñez); Amparito, 20 anys, oficiala (Vicenta Cruz); Jaume, 57 anys, pare de María i oncle de Doloretes, no li agrada treballar (Manuel Taberner); Atilano-Dracón, 45 anys, valent amb els febles i covard amb els forts (José Martí); Tomaset, 18 anys, carboner (Evaristo Santafé) i Visantico, 11 anys (Amparito Rocatí). En resum, sis personatges femenins i cinc masculins, tot i que Visantico, com veiem, es representat per una dona. L'acció té lloc a València, a l'època actual, concretament, en un taller de modistes.

L'argument és senzill, no hi ha dubte, estem, tal com ha indicat Hormigón, al taller de costura de Maria i Doloretes, que esperen l'arribada de la resta de treballadores.

\begin{abstract}
Al taller de costura de María y Doloretes van llegando oficiales, creando un ambiente colorista y encantador, animado por las canciones de Jaume cantadas por Amparito, «el rusiseñor del taller». Cuando llega la maestra, todas ponen su perra gorda en la caja común con la que piensan ir a tomar una paella al Saler. Echan en falta a Marieta, la aprendiza, que llega tarde y acompañada de su hermano Visantico. Los dos niños cuentan la pobreza y las necesidades que pasan en su casa. Ante tan triste situación, todas deciden entregarle la caja de la paella y ayudar a la pobre família. Es un sainete sencillo, con la usual exposición de tipos costrumbristas, mínima acción y sentimentalismo melodramático que elude, aludiéndonos, los problemes sociales. No hay en realidad acción dramática ni carácteres, sinó un cuadro simplón de supuestas costumbres populares encarnadas en personajes tópicos. La posibilidad de crítica social queda desvirtuada gracias al colectivo corazón de oro de las modistillas. Teatro viejo ya en su época, no tiene más valores que el tipismo costrumbrista (y éste es muy escaso) (Hormigón 1996: 890-891).
\end{abstract}

REVISTA VALENCIANA DE FILOLOGIA / IV (2020) p. 95-IO8

ROBERT MARCH

Pilar Monzó de la Roca, dona sainetera / ıо० 
Al nostre parer, a més del comentari d'Hormigón, considerem que cal insistir en el fet que siga una dona qui prenga les regnes de la situació. Parlem de l'escena IX. Es tracta del moment en què el personatge d'Atilano, qui té un deute econòmic amb el taller, es queixa, amb el bastó a la mà, del preu que ha de pagar per una nova peça de roba. El més rellevant és com Doloretes fa recular la violència d'Atilano. Per tant, més enllà del conflicte entre classes socials, que sol abastar el gènere del sainet, cal tenir en ment com un personatge femení roman per sobre d'un masculí, tot just, gràcies al joc teatral. En altres paraules, Monzó, mitjançant l'escena, amb dramatisme o sense i amb certs matisos humorístics en alguns casos, aconsegueix situar el personatge d'una dona, Doloretes, per sobre del d'un home, Atilano, caracteritzat per Monzó, com déiem abans, com a valent amb els febles i covard amb els forts.

Atilano: [...] Ruín modista, no le pagaré esta cuenta, que sube más que mi mujer.

Doloretes: Es clar, viu en la planta baixa...

Atilano: ¡A mí no me interrumpe nadie! (A María.)

Doloretes: ¿Usted pide once duros?

María: Sí, señor; es lo último.

Atilano: Lo último va a ser su cabeza de usted, si no me rebaja treinta pesetas!

María: No puedo rebajarle nada.

Atilano: ¿Nada?... Ha dicho usted nada?... Ahora mismo van a saber en esta casa quién es don Atilano Dracón. (Todas se levantan y se arrugapn tras el velador. Jaume y Visanteta se amurallan tras la madera de hilvanar.)

María: (Suplicante.) ¡Por Dios, don Atilano!... Si no gano casi nada cobrándole once duros...

Atilano: ¿Once duros?... ¡Once bastonazos!... ¡No saldré de esta casa sin prenderle fuego por los cuatro costados!

Jaume: (Asomando la cabeza.) ¡Sóltali el bou doloretes!

Doloretes: (Arrogante.) ¡El que ardix ara mateix es vosté mal educat!

Atilano: ¿Qué dice esta mujer?... ¡Yo me la como!

REVISTA VALENCIANA DE FILOLOGIA / IV (2020) p. 95-IO8

ROBERT MARCH

Pilar Monzó de la Roca, dona sainetera / IOI 
Doloretes: (Acercándose a él.) ¡Vosté no’s mencha ni un merengue. Y no s'el mencha, perquè ara mateix li arranque la dentadura en dos trompaes! (Le quita el bastón. Atilano: ¡Esta mujer es un veragua! (Atilano inicia su transformación, hasta quedar completamente acobardado.)

Doloretes: ¡A callar!... Ya sabem en esta casa que abans que chagant ha segut vosté nano.

Atilano: ¿Nano yo?... ¿Yo nano? (Jaume tararea el baile de los cabezudos.) Jaume: ¡Perretes, perretes!

Doloretes: Sí, senyor; nano y ben nano... Y està vosté soltant els onse duros si no vol tornar a casa coixechant... ¡La sort que tenen estos tips per a chillar tant, es qu'els atres callen masa!

Atilano: Voto a...

Doloretes: No vote, qu'es trencarà els calsetins... Y com li torne a pegar a donya Resignación...

Jaume: Li ho direm al sereno del seu barrio, qu'es molt amic meu.

Visanteta: Y el portará al Asilo...

Atilano: (Humilde.) Bueno; rebájeme usted algo...

Doloretes: Ni un sentim. Y si no paga en seguida sabrá tota Valensia qui es vosté. (Entrega el bastón a Jaume.)

Jaume: (Tomando el bastón por tizona y declamando trágicamente.) No n'hauríen en lo mon, / tan roïns y tan infames, / si als miserables que son/ Atilano Dracon, / els deixaren sense cames.

Visanteta: ¡Aixó no es cuarteta; això es un quintal!

Atilano: (Hecho un corderillo.) ¡Si t'en falta algí, el decapite per la sintura! (Doloretes cuenta el dinero y lo entrega a María.)

Atilano: Ya me voy... (Inicia el mutis. Todos le insultaran hasta verle desaparecer. Jaume le acompaña.)

Doloretes: ¡Felís viache!

Roseta; ¡Adiós, colom sense fel!

Amparito: Cuan arribe, no cal qu'escriga... (Mutis de Atilano.)

(Monzó 1930: 21-23).

A més, hi ha un altre aspecte que també voldríem remarcar dels personatges femenins en La falta de Marieta, que Monzó ens els presenta com a

REVISTA VALENCIANA DE FILOLOGIA / IV (2020) p. 95-IO8

ROBERT MARCH

Pilar Monzó de la Roca, dona sainetera / IO2 
treballadores dignes i amb aspiracions. Parlem, sobretot, de Visanteta i Roseta. La primera, com a Jaume, li agraden les lletres, escriu i desitjaria poder ser escriptora; la segona, en canvi, desitjaria tenir un altre nom, voldria ser Conchita Arenal. Com veiem, tot i que siga mitjançant el to còmic típic del sainet, Monzó introdueix la professió liberal d'escriptora per al cas de Visanteta i el nom de Conchita Arenal, diplomada en dret, feminista, poeta i dramaturga del segle XIX, per a Roseta. Trets aquests que podrien pensar-se, especulem, com a propis d'una Pilar Monzó que, tot i remetre als tòpics del gènere, es serveix del teatre, almenys ací, per a dibuixar uns personatges no tan superficials com poden semblar en un primer moment.

\section{4. 'Visanteta' (1930, Salón Novedades)}

Estrenada en el Salón Novedades el 13 de novembre de 1930 i publicada en el setmanari literari Nostre Teatro, dirigit per Jesús Morante Borrás, el 17 de gener de 1931, en el núm. 11 de la col-lecció de l'editorial Carceller. Si La falta de Marieta presentava una dedicatòria a l'actor Manuel Taberner, Monzó dedica Visanteta a Vicenta Silvestre, protagonista de l'obra, que, a més, havia interpretat el personatge, amb el mateix nom, en el sainet anterior. Ara bé, a diferència de La falta de Marieta, la publicació de Nostre Teatro inclou unes paraules de Monzó, amb què ens informa del propòsit d'escriptura del text i, alhora, l'homenatge que li ret a l'actriu. ${ }^{5}$

Me vaig proposar al escriure esta comèdia, demostrar la meua gratitud a la señora Silvestre, per la creació que feu en un tipo del primer sainet que vaig escriure. Al mateix temps, també me vaig proposar donar reals al tipo de dóna, que veu transcurrir els dies, sense vore halagá per un voler, la seua extistensia plena de sacrificis y renunsia-

5 En la pàgina 13, en una nota a peu de pàgina, trobem també un altre agraïment, en aquest cas, al Sr. Llorens per la seua interpretació del personatge de Furtacoques.

REVISTA VALENCIANA DE FILOLOGIA / IV (2020) p. 95-IO8

ROBERT MARCH

Pilar Monzó de la Roca, dona sainetera / IO3 
ments... Este era el propósit que segurament no he lograt. Primer, per que com a ofrena, es pobrísima, y después, per que en literatura, lo que me sobra en voluntat, me falta en mérits per a descriure com es degut, el tipo de la heroína que sols mereix l'admirasió i cariño de tots. (Monzó 1930: 3)

Ben interessants són les paraules de Monzó que remeten no ja cap al producte final d'aquest sainet, sinó, més aviat, a la concepció que la dramaturga sent sobre el text, que, al nostre parer, en termes de qualitat, seria inferior a La falta de Marieta.

Comptem ara amb nou personatges, tres femenins i sis masculins. Aquests són els següents: Visanteta, 35 anys (Sra. Silvestre); Fifí, 18 anys (Srta. Mateo); Dorín, 21 anys (Sra Rocatí); Rafel, 40 anys (Sr. Martí); Ramon, 65 anys (Sr. Cabrera); Rodrigo, 25 anys (Sr. Sánchez); Manolito, 21 anys (Sr. Benítez); Furtacoques - aguasil (Sr. Llorens) i un Cartero (Sr. Llácer). Tal com ocorria en La falta de Marieta, també Visanteta es divideix en onze escenes, tot i que, en aquest cas, no mitjançant una distribució numèrica, sinó amb l'ajuda de línies horitzontals, que incorporen el nom dels personatges. Les escenes completen l'acte únic i el text abasta dotze pàgines a dues columnes per pàgina. L'espai, també com en el cas anterior, se situa en l'actualitat dels anys trenta. L'acció, en canvi, a Beniloto, un poble inventat, «que se supón prop de Valensia», tal com indica Monzó.

Tot i que en aquest article no entrarem a esmentar els aspectes lingüístics, sí que voldríem afegir una observació en relació amb les acotacions, ja que, a diferència del sainet anterior, aquestes se'ns presenten ací en valencià, prenormatiu, és clar. L'acotació inicial és la següent:

Planta Baixa d'una casa de poble aon pasen l'estiu Ramon Bueno y la seua família. Porta al foro y laterals a dreta y esquerra la del actor. En un ángul de la essena, un velaoret. Damunt de este velaor, una nina de regulars dimensions. Algunes cahires y en primer terme, un silló de mimbre. (Monzó 1930: 4)

REVISTA VALENCIANA DE FILOLOGIA / IV (2020) p. 95-IO8 ROBERT MARCH Pilar Monzó de la Roca, dona sainetera / IO4 
De la mateixa manera que Monzó ens oferia un conflicte econòmic en La falta de Marieta, també els diners són una constant en Visanteta. De fet, també en relació amb un deute, concretament, el que té Ramón — pare de Visanteta, Fifí i Dorín-, amb Rafel, alcalde de Beniloto, un home a qui ningú estima fins que guanya el premi de la grossa de Nadal. Rafel, a més, és propietari del pis de Ramón.

D’acord amb Hormigón, Monzó realitza una crítica a la petita burgesia, ja que l'origen del deute el trobem en el malbaratament de diners per part de Fifí (Josefina) i Dorín (Salvadora), sempre pendents d'aparentar i d'estiuejar, sobretot, en la font de l'Ermita. Aquests personatges, defugen del seu nom, cosa que no li agrada a Rodrigo, pretendent de Salvadora.

Rodrigo: Encontre un poc ridícul eixe anhel de disfrasaro tot... Desde el nom, hasta els sentiments que moltes vegaes, rist es confesaro, els cubrim baix la capa de la hipocresia... Tenim el gust de apareixer ant el mon, en maneres de dimoni... cuant en realitat, es un ánchel lo que viu en nostre cor (Monzó 1930: 9)

En tot cas, a més de les aparences que determinen la resolució del sainet, hi ha diferents aspectes que cal esmentar. I és que, també com abans, serà un personatge femení, Visanteta, qui encare la situació, açò és, qui dialogue amb Rafel, perquè tinga paciència amb el cobrament. Com ocorria amb la Doloretes de La falta de Marieta, és una dona qui planta cara al conflicte. Ara bé, entenem que existeixen diferències en la caricaturització d'ambdós personatges, no en un inici, sinó en la transformació que pateix tant Visanteta com Rafel. Ella, major per a casar-se i ell, potser, un analfabet que, com hem assenyalat, no és estimat fins que no té diners.

Ramon: Es veritat. Per tú vullc viure, per tú. Pero, qué li dic yo a eixe casero sense ánima.

Visanteta: Yo el resibiré. Parlaré en ell, y li diré que s'espere tres dies.

Ramon: Y qué farem en eixos tres dies.

REVISTA VALENCIANA DE FILOLOGIA / IV (2020) p. 95-IO8

ROBERT MARCH

Pilar Monzó de la Roca, dona sainetera / I05 
Visanteta: Demá li demanaré dos pessetes a la señora Julia la veïna. Aniré a Valensia, vendré 1 adrés de la mare, y de lo que me donen, li pagarem a don Rafelo.

Ramon: Qué bona eres, Viantenta!... No te fa dol despéndret de l'ahulleta de ta mare?

Visantenta: Més dol me fa voret patir. Si no som útils als demés, per a qué volem viure?

Visanteta: Ara te chites un ratet. Si ve don Rafelo, ya me hu apañaré yo per a que te deixe tranquil hasta que li paguem.

Ramon; No voldrá esperarse. Es molt bruto.

Visanteta: Yo li parlaré en cariño. M'arreglaré el moño, me mudaré ben mudaeta, y vorás...

Ramon: Pero si no tens ningún trache nou, Visanteta.

Visanteta: Pero ne tinc uno molt netet.

Ramon: Un netet que ya es agüelo de tants añs qu'el tens.

Visanteta: No li fa.

Ramon: Ves, filla meua ves. Arreglat y a vore si tens grasia pa torechar a eixe alcalde miureño.

Visanteta: Si qu'el torecharé be, si. Ya vorás com al meu costat Barrera, es un burladero.

(Monzó 1930:7-8).

En tot cas, si Visanteta sembla estar pròxima a Doloretes, en la mesura en què avança el sainet, es distancia de la seua homònima, tant que capgirarà l'actitud de Rafel i, ambdós, després de l'encontre, acaben enamorant-se i celebrant el goig fins la cloenda de l'obra. De fet, una vegada Rafel demane la seua mà, el deute no únicament queda en l'oblit, sinó que, a més, regala a Ramon la casa en què viu i, per si això no fora prou, dona a Visanteta la vara de l'Ajuntament, «Tu eres l'ama d'esta vara y d'este home» (Monzó 1930: 15), tot i que ella li la torna finalment: "Teua es. Goberna al poble en chustisia y dignitat... Yo governaré ma casa en humiltat y en amor...» (Monzó 1930: 15). Visanteta, com la ventafocs — «Fifí: Visanteta, no me deixes sense planchar la bata blan-

REVISTA VALENCIANA DE FILOLOGIA / IV (2020) p. 95-IO8

ROBERT MARCH

Pilar Monzó de la Roca, dona sainetera / I06 
ca» (Monzó 1930: 7), ${ }^{6}$ amb l'amor correspost de Rafel, aconsegueix pujar en l'escala social, això sí, sense que el matrimoni, com a institució d'organització social — també Rodrigo, que és mestre, es casarà amb Salvadora-, reba cap tipus de qüestionament. Més aviat el missatge és el següent: «Y sempre per el camí del be, que conduix a la felisitat que no mor».

\section{Conclusió}

Conscients, però, que només hem prestat atenció a dos dels nou sainets de Pilar Monzó, observem que hi ha semblances entre alguns personatges femenins, que, com hem assenyalat anteriorment, prenen les regnes de la situació. Ara bé, tot i les dificultats en la documentació, entenem que caldria realitzar una lectura comparativa amb els altres textos publicats (L'amo, ed. Carceller, 1931; El geni de la tana, Nostre Teatro, núm. 15, 1931 i Pare! Pare!, Nostre Teatro, núm. 64,1932 ) per a comprovar, com a mínim, si la tendència emprada en la caracterització dels personatges femenins de La falta de Marieta i Visanteta apareix en la resta de sainets. En aquest cas, potser, podríem obtenir una informació més valuosa i, sobretot, més interessant a l'hora d'esbrinar la creativitat de Monzó des d'una perspectiva més àmplia i, per tant, establir unes conclusions més fermes. És a dir, veure si l'idiolecte dels personatges pot donar-nos alguna clau que puga definir millor l'escriptura de l'autora.

6 Visanteta: [...] Mon pare adorava a la seua primera dona, qu'era ma mare... Morí aquella santa, y deu añs despues, tornà a casarse en la mare de les meues chermanes. També Deu se li emportá a la segon dona; y desd'entonses, mon pare y yo, sols ham vixcut per a colmar les ilusións de les chiquetes. Elles han creixcut... han creixcut en elles les ambicions de la choventut que yo may he gochat (Monzó 1930: 11).

REVISTA VALENCIANA DE FILOLOGIA / IV (2020) p. 95-IO8

ROBERT MARCH

Pilar Monzó de la Roca, dona sainetera / I07 


\section{Bibliografia}

Arias, Fernando (1999) La Valencia de los años 30, València, Arts Gràfiques.

Diccionari biogràfic de dones, Xarxa Vives d'Universitats / Generalitat de Catalunya / Consell de Mallorca. [http://www.dbd.cat/fitxa_biografies.php?id=66] (Darrera consulta: maig de 2020).

Guastavino, Severino; Guastavino, Guillermo (1974) Un siglo de teatro valenciano. Materiales para su estudio, t. LXxviI, Madrid, separata de la Revista de Archivos, Bibliotecas y Museos.

Hormigón, Juan Antonio; Alvear, Inmaculada; Rodríguez, Carlos (1996) Autoras en la historia del teatro español, vol. II, s. xx, Madrid, Asociación de Directores de Escena de España.

Lacueva, Maria (2013) Elles prenen la paraula. Recuperació $i$ crítica a les aules de les escriptores valencianes: una perspectiva des de l'educació literària, tesi doctoral, Facultat de Magisteri, Universitat de València.

Monzó, Pilar (1930) La falta de Marieta, València, Imprenta La Gutenberg.

- (1931) Visanteta, València, Nostre Teatro.

Roig, Rosa; Lluc, Violeta (2019) «Pilar Monzó de Roca i les saineteres valencianes. Reparació d'un oblit», Una metàfora de la vida, València: Associació Cultural Bda. Sda. Família Corea. [https://issuu.com/llibretcorea2019/docs/llibret_corea_2019] (Darrera consulta: maig de 2020)

SANSANO, Gabriel (2014) Inventari bibliogràfic informatitzat del teatre popular valencià dels segles XIX I XX (1817-1850). [http://instantaneo.es/wiki/index.php/Teatre_Popular_Valenci\% $3 \% \mathrm{~A} 0]$

SolÀ i Palerm, Caterina (1976) El teatre valencià durant la dictadura (1920-1930), Barcelona, Publicacions de l'Institut del Teatre.

REVISTA VALENCIANA DE FILOLOGIA / IV (2020) p. 95-IO8

ROBERT MARCH

Pilar Monzó de la Roca, dona sainetera / Io8 